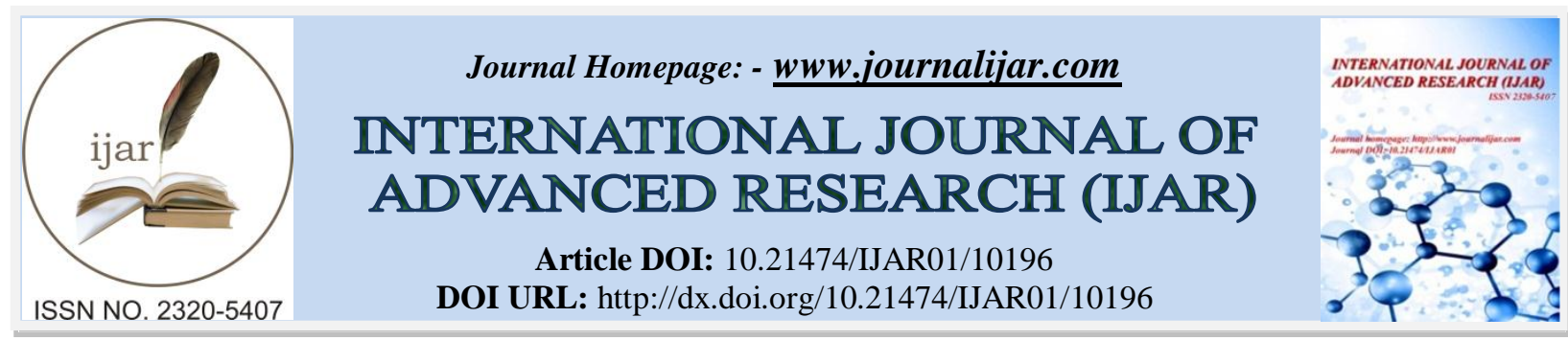

RESEARCH ARTICLE

\title{
GREEN SYNTHESIS AND CHARACTERIZATION OF ZINC OXIDE NANOPARTICLES USING CASSIA ARTICULATE FLOWER EXTRACT
}

Srimeena S. and Nithya $S$

Department of Chemistry \& Physics, Nadar Saraswathi College of Arts \& Science for women.

\section{Manuscript Info}

\section{Manuscript History}

Received: 10 October 2019

Final Accepted: 12 November 2019

Published: December 2019

Key words:-

Cassia Articulate, Zirconium oxide, FTIR, XRD, SEM
Abstract

Zinc oxide $(\mathrm{ZnO})$ nanoparticles were prepared by using green synthesis method. The prepared nanoparticles were characterized by using Fourier transform infrared spectroscopy (FTIR). The wave number 828 $\mathrm{cm}^{-}{ }^{1}$ indicated the presence of the zinc oxide nanoparticles. The average crystallite sizes were calculated by applying sheer equation on the base of XRD powder patterns of all samples and found to be in the range $38.11 \mathrm{~nm}$. This is order in nanosize. In accordance with the SEM image would like that rock in shape.

Copy Right, IJAR, 2019,. All rights reserved.

\section{Introduction:-}

$\mathrm{ZnO}$ is an inorganic compound with the formula $\mathrm{ZnO}$.It usually appears as yellow powder nearly. Insoluble in water [1]. The powder is widely used as an additive into numerous materials and products including plastics, ceramics, glass, cement, rubbers, lubricants, paints, ointments, adhesives, sea lands, pigments, foods, batteries, fire retardants etc [2]. $\mathrm{ZnO}$ is present in the earth crust as mineral zincates however most $\mathrm{ZnO}$ used commercially is produced synthetically. Zinc oxide $(\mathrm{ZnO})$ nanopowders are available as powders and dispersions [3]. These nanoparticles exhibit antibacterial, anti-corrosive, antifungal and UV filtering properties.

\section{Experimental Procedure:-}

\section{Preparations of Zinc Nanoparticles}

The synthesis nanoparticles $50 \mathrm{ml}$ of cassia articulate flower extract was taken and boiled to $60^{\circ} \mathrm{c}$ using a stirrer heater. $5 \mathrm{~g}$ of zinc nitrate was added to the solution as the temperature reached $60^{\circ} \mathrm{c}$. The mixture is then boiled in 1hour and then the mixture collected in a $100 \mathrm{ml}$ beaker and heated in an air heated furnace at $150^{\circ} \mathrm{c}$ for $5 \mathrm{hours}$. A yellow colored powder was obtained and this was carefully collected and packed for characterization purposes. The material was mashed in a mortar-pestle so as to get a finer nature for characterization.

\section{Results And Discussion:-}

Vibrational Studies:

Fourier Trans Form Infrared Spectroscopy:

The synthesized $\mathrm{ZnO}$ powder was further supported by FTIR spectra.

Corresponding Author:- Srimeena S

Address:- Department of Chemistry \& Physics, Nadar Saraswathi College of Arts \& Science for women. 


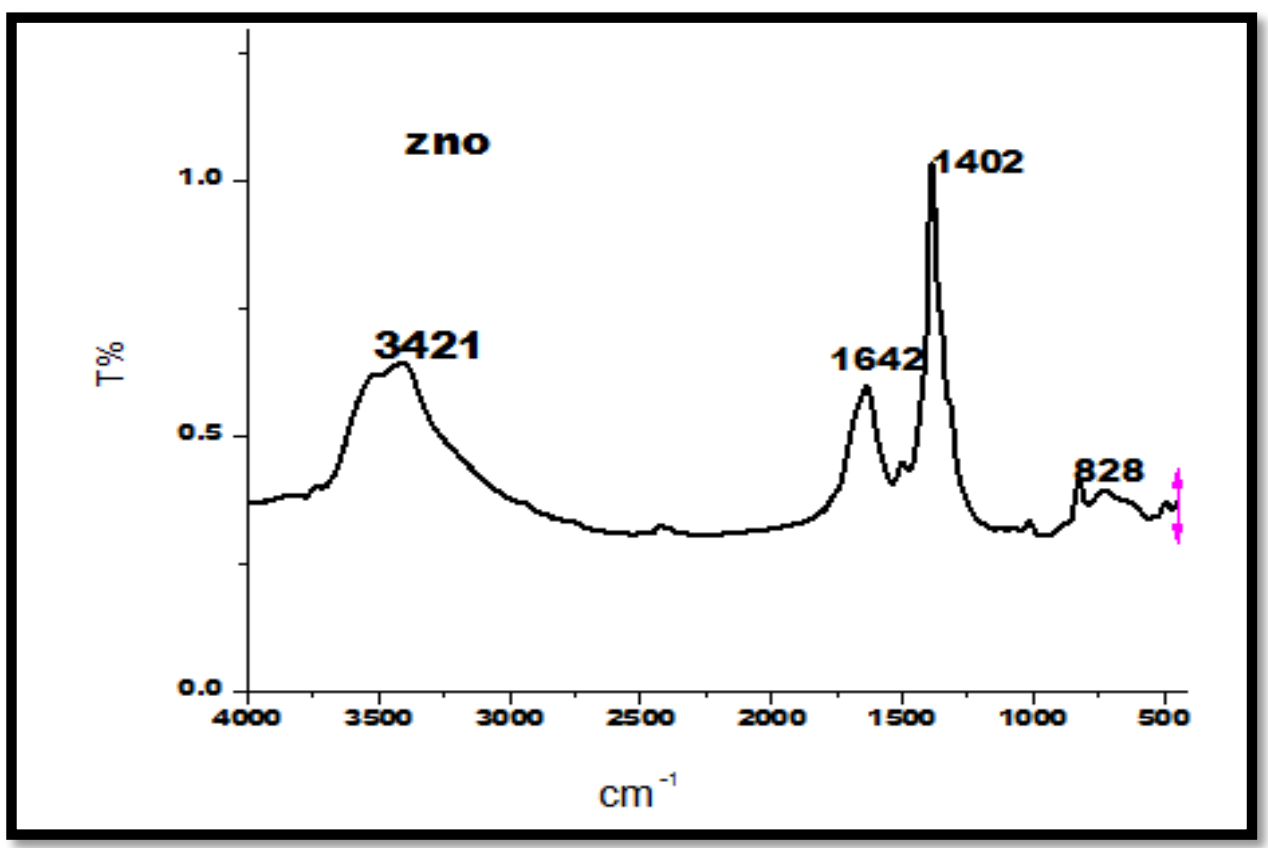

Fig 1:- FTIR spectrum of (Zno) nano particle.

The FTIR Spectrums of the (Zno) samples are shown in fig (1). The absorption peak at very large band around $3421 \mathrm{~cm}^{-1}$ is attributed to the stretching of O-H stretch, The small absorption peaks at C-O stretch bend $1642 \mathrm{~cm}^{-}{ }^{1}$. The strong absorption peak between $828 \mathrm{~cm}^{-1}-842 \mathrm{~cm}^{-1}$ indicate the $(\mathrm{ZnO})$ nanoparticles.[4]

\section{Structural Studies:-}

X-ray diffraction:

It shows that XRD pattern of the zinc oxide nanoparticle obtained by green synthesis method. The major phase corresponds to the (200), (220),(221) lattice plane. The (hkl) values are agreed well with the standard card of $\mathrm{ZnO}$ powder sample (JCPDS file no: 772414). The crystallite average size D of the prepared nanopowder can be calculated by using Debye Scherer's formula

$\mathrm{D}=\kappa \lambda / \beta \cos \Theta$ Where $\lambda$ is the wavelength of $\mathrm{X}$ rays used (1.54060 $\AA$ ), $\beta$ is the full width at half maximum (FWHM) $=0.24,0.78,1.18$ and $\Theta$ is the angle of diffraction. The crystallite average size of prepared nanopowder is found to be around $38.11 \mathrm{~nm}$ which is order in nanosized. [5].

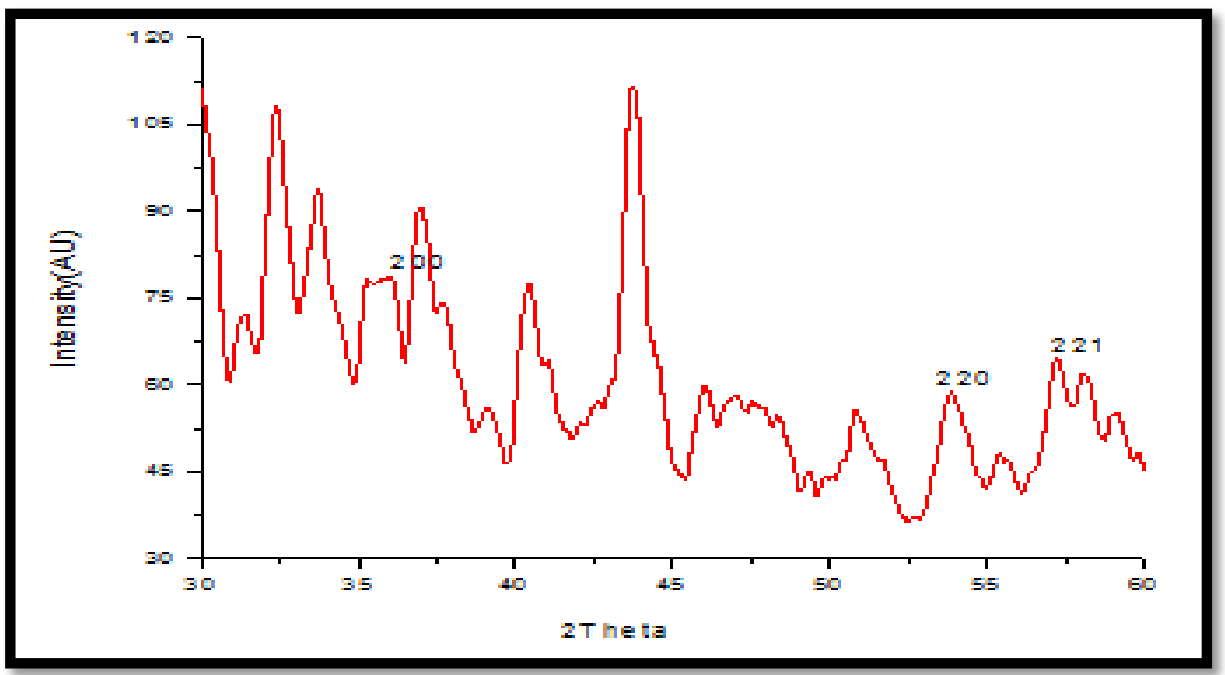

Fig 2:- XRD Pattern of (Zno) nano particle. 
Morphological Studies:-

Scanning Electron Microscope:

SEM studies were revealed to visualize the size and shape of zinc oxide nanoparticles and show the typical brightfield SEM microscope of the synthesized zinc oxide nanoparticles. In this study, it was appeared with that most of rock in shape. [6]

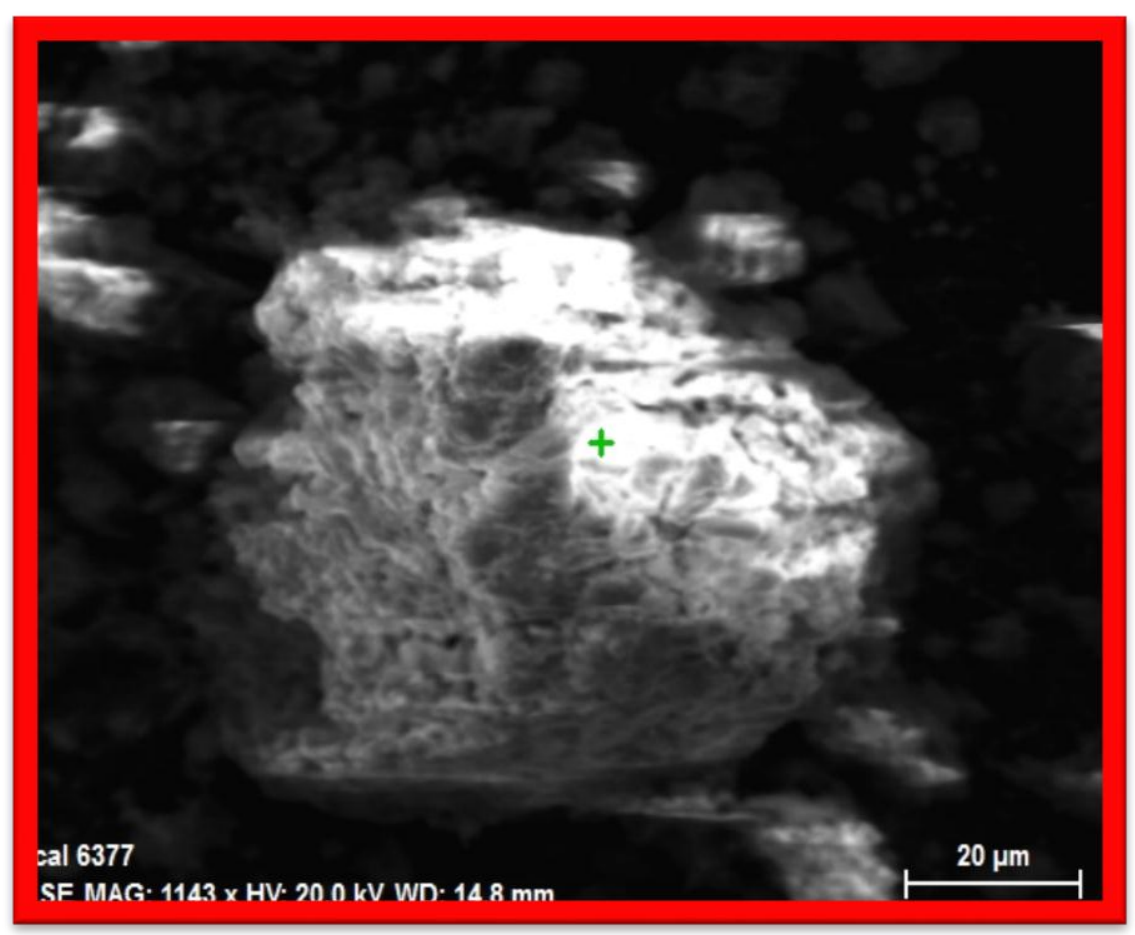

Fig 3:- SEM image of (ZnO) nanoparticles.

Edax (Energy Dispersive X-Ray Spectroscopy):

If confirm the structure element of aqueous extract of cassia articulate zinc oxide nanoparticles by green synthesis was carried

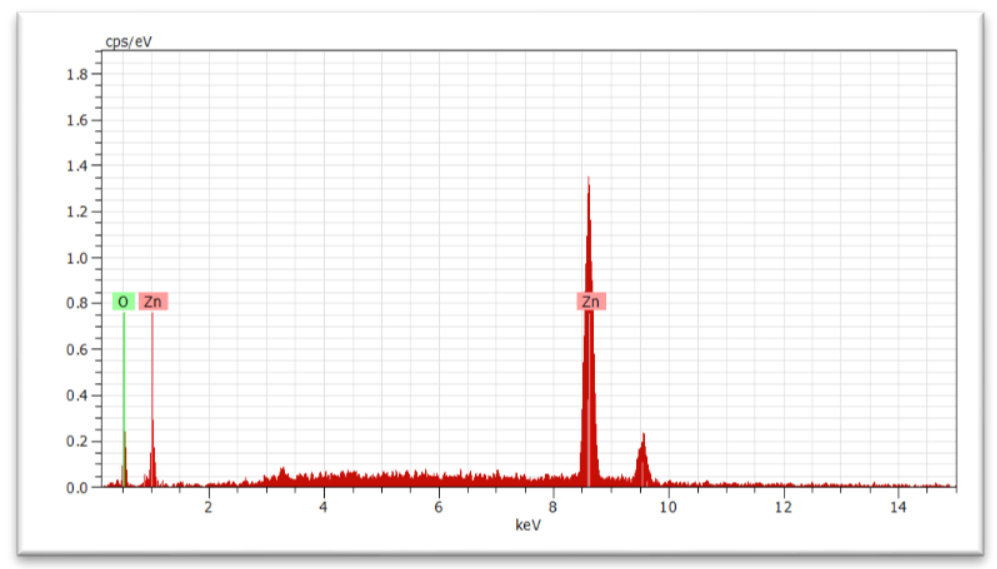

Fig 4:- EDAX image of $(\mathrm{ZnO})$ nanoparticles.

\section{Conclusion:-}

Fourier transforms infrared spectroscopy (FTIR). The wave number $828 \mathrm{~cm}^{-1}$ indicated the presence of the zinc oxide nanoparticles. The average crystallite sizes were calculated by applying sheer equation on the base of XRD 
powder patterns of all samples and found to be in the range $38.11 \mathrm{~nm}$. This is order in nanosized. In accordance with the SEM image would like that rock in shape. The EDX indicated the presence of $(\mathrm{Zr}, \mathrm{Cl}$, and $\mathrm{O})$. $\mathrm{ZnO}$ nanoparticles are prepared with help of the green synthesis method by using flower extract of Cassis Auricular. Green synthesis method is simple, non toxic.

\section{References:-}

1. Pai AR, Kavita S, S.Sh. Raj, and Sasidharan S.Green synthesis and characterization of silvernanoparticles using fresh leaf extract of Morindacitrifoliaand its antimicrobial activities studies.Int. J. Pharm. Pharm. Sci. 2015; 7(3), 459-461.

2. Saranyadevi K, Subha V, Ravindran RSE andRangnathan S. Green synthesis andcharacterization of silver nanoparticles leaf extract

3. EI. D.S.A. Tahar AA, Elzatahry D.M. A. Dhayan,AI-E.M. Addullah and S.A. Deyab and Saleem.Synthesis and characterization of magnetite zeolitenano composite. Int. J. Electrochem. 2011; 6,6177-6183.

4. Jianet. al., A study of ZnFe2O4nanoparticlesmodified by ferric nitrate. J Mag Magn Mater2013; 330: 96-100.

5. Alagummuthu G, Kirubha R. Green synthesis ofsilver nanoparticles using Cissusquadrangularisplant extract and their antibacterial activity. Int. J.Nano Mat Bio. 2012; 2 (3): 30-33.

6. Sundaravadivelan C, Nalini M. Biolarvicidal effectof phylosynthesized silver nanoparticles usingPedilanthustithymaloides(L) poit stem extractagainst the degree vector Aedesaegyptil (Diptera. 